RUNNING HEAD: PRODUCING COMPOSITES REMOTELY

PAPER PUBLISHED IN PSYCHOLOGY, CRIME \& LAW

http://dx.doi.org/10.1080/1068316X.2013.793339

Producing facial composite sketches in remote Cognitive Interviews: A preliminary investigation

Heidi J. Kuivaniemi-Smith ${ }^{1}$, Robert A. Nash ${ }^{2 *}$, Eleanor R. Brodie ${ }^{2}$, Gregory Mahoney $^{1,3}$, \& Christopher Rynn ${ }^{1}$

${ }^{1}$ Centre for Anatomy and Human Identification, University of Dundee, UK

${ }^{2}$ School of Psychology, University of Surrey, UK

${ }^{3}$ Boston Police Department, Boston, MA, USA

* Corresponding author

Dr. Robert A. Nash

School of Psychology

University of Surrey

Guildford

Surrey, GU2 7XH

United Kingdom

Tel: (+44) 1483686884

Email: R.Nash@surrey.ac.uk 


\begin{abstract}
Justice systems around the world are increasingly turning to videoconferencing as a means to reduce delays and reduce costs in legal processes. This preliminary research examined whether interviewing a witness remotely-without physical co-presence of the witness and interviewer-could facilitate the production of quality facial composite sketches of suspects. In Study 1, 42 adults briefly viewed a photograph of a face. The next day they participated in Cognitive Interviews with a forensic artist, conducted either face-to-face or remotely via videoconference. In Study 2, 20 adults participated in videoconferenced interviews, and we manipulated the method by which they viewed the developing sketch. In both studies, independent groups of volunteers rated the likeness of the composites to the original photographs. The data suggest that remote interviews elicited effective composites; however, in Study 1 these composites were considered poorer matches to the photographs than were those produced in face-to-face interviews. The differences were small, but significant. Participants perceived several disadvantages to remote interviewing, but also several advantages including less pressure and better concentration. The results of Study 2 suggested that different sketch presentation methods offered different benefits. We propose that remote interviewing could be a useful tool for investigators in certain circumstances.
\end{abstract}

Key words: face composite; Cognitive Interviewing; video-mediated communication; eyewitness memory; sketch artist. 


\section{Producing facial composite sketches in remote Cognitive Interviews: A preliminary investigation}

The judicial system as it appears today is the product of many centuries of legal evolution. Yet in recent years, the system has been undergoing a vast technological revolution. Just one example of this transformation is the use of videoconferencing, now used increasingly in several countries-USA, UK, India, Australia, New Zealand, and others - to permit witnesses, victims and suspects to testify in court without being physically present (Johnson \& Wiggins, 2006). In this paper we report preliminary data regarding another potentially useful novel application for videoconferencing technology in the legal process. Specifically, we ask whether videoconferencing could be used in investigative interviews with witnesses, for the purposes of creating effective composite sketches of suspects.

\section{Composite techniques}

Facial composites have been valuable to police investigations for over a century (Davies \& Valentine, 2007). Whereas the 'original' method for producing composites involved sketch artists, the high demand for and shortage of such artists led to the design of mechanical systems such as Identikit and Photofit, followed by software systems such as Mac-a-Mug, E-FIT and EvoFIT (see Davies \& Valentine, 2007; McQuiston-Surrett, Topp, \& Malpass, 2006). Despite these developments, sketch artistry remains the benchmark that no other technique has consistently outperformed in empirical studies: indeed, in Frowd et al.'s (2005) research, sketch artists produced substantially better composites than did all the software systems tested.

Irrespective of the method used, the production of quality composites depends heavily on effective interviewing techniques. In the UK and elsewhere, frontline 
police officers are trained in Cognitive Interviewing: an investigative technique that elicits substantially more correct information from witnesses than do 'standard' interviewing procedures, without compromising accuracy (Köhnken, Milne, Memon, \& Bull, 1999; Memon, Meissner, \& Fraser, 2010). The UK Association of Chief Police Officers' (2009) guidelines require that (adapted) Cognitive Interviews are used when creating facial composites from witnesses' descriptions; the International Association for Identification, too, recommends that forensic artists use this technique (Richardson, Stahl, Deal, \& Lowe, 2010). Cognitive Interviews - whether used for eliciting facial descriptions or narrative accounts - are typically conducted face-toface. However, the legal system might reap several benefits in certain cases by conducting interviews remotely, that is, without the witness and interviewer being physically collocated.

\section{Video-mediated communication (VMC)}

The use of videoconferencing technology has boomed in recent years, not least in legal domains. As noted above, governmental and intergovernmental institutions are increasingly turning to videoconferencing as a solution to organizational problems in the judicial system (Johnson \& Wiggins, 2006). For example, it has been argued that VMC can permit reductions in certain costs, particularly in cases that involve co-operation of agents across multiple states or nations (e.g., Council of the European Union, 2009). VMC might also permit witnesses to be interviewed by expertly-trained interviewers and sketch artists when no expert is available locally. Interrelated with both of these possibilities is the broader notion that VMC technology could help to reduce delays in the legal process.

\section{Reducing delays}


Interviewing witnesses very soon after an incident occurs is not always possible (Frowd et al., 2005; Gabbert, Hope, \& Fisher, 2009). Demands on police time and resources, for example, mean that officers may be forced to prioritize key witnesses or other tasks (Hope, Gabbert, \& Fisher, 2011). Nevertheless, reducing delays in investigations is critically important. The longer the retention period before a witness is interviewed, the more the witness is likely to forget (Deffenbacher, Bornstein, McGorty, \& Penrod, 2008; Ebbinghaus, 1885), and the more plausible that their memory would be contaminated by misinformation from external sources (e.g., Zajac \& Henderson, 2009). Indeed, as retention interval increases, witnesses provide less detailed descriptions (Ellis, Shepherd, \& Davies, 1980), and their ability to identify offenders decreases substantially (Shapiro \& Penrod, 1986; Shepherd, Gibling, \& Ellis, 1991). When mock witnesses create composites just minutes or hours after seeing a target face, these are only correctly identified by individuals who are familiar with the target in around $20 \%$ of cases; yet when the composites are constructed after a 2-day delay, this identification rate falls to almost zero (Frowd, Bruce, \& Hancock, 2008). In sum, reducing delays prior to conducting interviews would undoubtedly lead to better composites, not to mention the benefits of publicizing the composites sooner with regard to catching culprits.

\section{Possible effects of VMC on investigative interviews}

Despite the plausible benefits of using VMC, there are reasons to expect that investigators would be wary of conducting interviews remotely. For instance, many people — both legal professionals and laypeople — believe that VMC negatively affects the ability to build rapport (Braun, 2011; Poulin, 2004). Indeed, this belief is substantiated by some empirical data, such as Fullwood's (2007; Fullwood \& Finn, 2010) finding that dyads who interacted remotely considered each other less likeable 
than did dyads who interacted face-to-face. Similarly, Straus, Miles, and Levesque (2001) found that job applicants interviewed remotely liked their interviewers less and felt less comfortable than did face-to-face interviewees. If current video-mediation technology damages rapport-building, then this effect would be extremely problematic for investigative interviewing, because research shows that interviewers who build rapport with witnesses elicit substantially more correct information, and less incorrect information (Collins, Lincoln, \& Frank, 2002; Vallano \& Schreiber Compo, 2011).

Another of Straus et al.'s (2001) findings was that video-mediated interactions can be disrupted by technical issues such as time-lags and image-freezing, and indeed their participants considered video-mediated conversations less fluent than face-toface conversations. Other authors too have found that technical issues caused communication problems in video-mediated interactions, although participants could counteract these problems to an extent by formalizing turn-taking with explicit 'handovers' (O’Conaill, Whittaker, \& Wilbur, 1993; O’Malley, Langton, Anderson, Doherty-Sneddon, \& Bruce, 1996). If video-mediation interrupts the fluency of interviews, this too might in turn harm the amount of detail witnesses provide.

Despite these reasons to expect poorer outcomes from video-mediated interviews, many studies have shown that VMC can support highly effective interpersonal interaction in various fields, including the provision of psychological therapy (Mitchell et al., 2008) and ‘distance-learning' (Storck \& Sproull, 1995). Indeed, even in the eyewitness domain, the results of one recent study suggest that video-mediated Cognitive Interviews can be just as effective as face-to-face interviews. In a mock-eyewitness study Nash, Houston, Ryan, and Woodger (2013) found that participants who were interviewed remotely reported just as much correct 
information as those interviewed face-to-face, with no additional incorrect detail. Furthermore, the two groups rated similarly their rapport with the interviewer, the interviewer's attentiveness, and their comfort during the interviews. In contrast to the predictions outlined above, then, these data might lead us to predict that effective facial composites could be created within remote Cognitive Interviews, perhaps to the same standard achieved in face-to-face interviews (see also Doherty-Sneddon \& McAuley, 2000 for similar findings from a study on the use of 'live-link' courtroom technology with children).

Nash et al.'s (2013) findings warrant optimism; however, it is plausible that VMC would be less efficacious for creating composites than for eliciting narratives as in their study. Research shows that people rely heavily on gestures when communicating information that is difficult to remember and describe verbally (Morsella \& Krauss, 2004): characteristics that are both true of faces (Brace, Pike, Allen, \& Kemp, 2006; Schooler \& Engstler-Schooler, 1990). Furthermore, because composite interviews require witnesses to see the developing composites and provide feedback, the clarity of this visual information might be impaired without physical copresence.

In sum, whereas remote interviewing may provide desirable benefits for the legal process, such as reducing delays and costs, there are reasons to predict that this medium would harm interviewers' ability to elicit detailed facial descriptions and produce effective composites. Yet if remote interviews could indeed be used to this end, then this technique could be invaluable. The present research begins to address this timely and important question.

\section{STUDY 1 - INTERVIEW PHASE}

Our first study served to examine the relative efficacy of face-to-face interviews 
and remote interviews conducted via videoconference.

\section{Method}

\section{Participants and Design}

A total of 42 students ( 5 males, 37 females; mean age $=20.80, S D=4.69$ )

received course credit or $£ 6$ for taking part. Each participant was randomly assigned to either the face-to-face or VMC interview condition. Most participants in the VMC condition (86\%) said they had used Skype ${ }^{\odot}$ before.

\section{Procedure}

Each participant individually attended two sessions on consecutive days.

Session 1. Each participant met with a researcher and was simply shown a frontal head-and-shoulders photograph of an unfamiliar person for 1 minute (from Minear \& Park, 2004). Each participant saw a different photo. Prior to viewing these photos, participants were told that they would be interviewed in Session 2, but were not explicitly told that they would be asked to recall and describe the face.

Session 2. Session 2 took place the following day. On their arrival, each participant was shown into an interview room by the same researcher from Session 1. Participants in the face-to-face condition were met inside the room by a second person, the interviewer (the first author). The interviewer was a forensic sketch artist who as part of a Masters degree in Forensic Art had received several weeks' training in Cognitive Interviewing by an experienced interviewer. Her specific Cognitive Interviewing training had been supplemented by extensive guided practice in using the technique, as well as more theoretical learning about facial anthropology and anatomy. A maximum of three participants were interviewed per day.

For participants in the VMC condition, the interviewer was not present in the interview room. Instead, they were simply asked to sit at a computer on which Skype ${ }^{\odot}$ 
web-conferencing software was running. Basic written instructions about how to use Skype $^{\odot}$ were provided for the participant, and the researcher helped the participant to $\log$ in. The researcher then left the participant alone in the room, and the interviewer-who was in another room — initiated a video-call with the participant involving two-way visual (via webcams) and audio communication. The interviewer conducted all of the interviews, and had not met any of the participants before the interviews, nor seen the target photos.

Aiding and eliciting the memory report. The interviewer began by ensuring that the participant could see and hear her suitably. All interviews then proceeded in accordance with an Enhanced Cognitive Interview protocol, as follows (Fisher \& Geiselman, 1992). Rapport was first established through informal and friendly conversation, and the interviewer explained that the participant's aim was to describe the face they saw by concentrating as hard as possible, to help the interviewer create an accurate sketch. Throughout the VMC interviews, and particularly during the rapport-building phases of these interviews, the interviewer simulated eye-contact by looking directly into the camera. The participant was instructed to describe everything they could remember, no matter how small, but not to guess details.

The participant was next guided through a context reinstatement exercise, to assist them to visualize the appearance of the person they saw. When the participant indicated that they had a satisfactory mental image, they were encouraged to provide a free and uninterrupted account.

Producing the sketch. Once the participant completed their free account, the interviewer began making a light sketch based on the description. She asked open questions to elicit more detail, beginning by establishing the facial proportions. Throughout the interview the sketch was shown to VMC participants in one of two 
different ways, as the interviewer saw fit. Sometimes the interviewer displayed the sketch to the webcam free-handedly; this method was typically used for evaluating smaller changes to the sketch. Other times the interviewer photographed the sketch using a digital camera, then uploaded this image and transferred it to the participant via Skype ${ }^{\odot}$. This method was always used for displaying the preliminary sketch, and also typically for larger changes. Participants were advised not to look at previouslysent images once a new one had been sent. Face-to-face participants could not see the developing sketch all the time; rather, they only saw it whenever the interviewer actively turned the sketchpad for them to scrutinize. All participants were shown the developing sketch as frequently as they requested.

The interviewer made brief notes of any changes to the preliminary sketch the participant suggested, and only began altering it once the participant finished their evaluation. To elicit further detail, both open and closed questions were used-we analyze the exact content of the questioning shortly. Once the sketch was welldeveloped, a facial catalogue - containing hundreds of reference images of faceswas provided to help the participant whenever they found verbalizing information difficult. ${ }^{1}$ In such circumstances, VMC participants were also encouraged to use the screen-sharing function in Skype $C$ so that they could use the mouse cursor to point to specific areas of the sketch.

Interviews ranged in duration from 43-120 minutes $(M=69.38$ minutes, $S D=$ 17.47). There was no significant difference between the durations of face-to-face interviews $(M=68.71$ minutes, $S D=19.35)$ and VMC interviews $(M=70.04$ minutes, $S D=15.83), t(40)=0.24, p=.81$. Immediately after the interviews, VMC participants

\footnotetext{
${ }^{1}$ We expect that real 'remote-witnesses' could be permitted to see facial catalogues electronically, but unfortunately we only had access to physical copies.
} 
privately completed a brief survey about their interview; we discuss their responses toward the end of this paper.

\section{Results}

Before considering the quality of the sketches produced, we first assessed whether there were systematic differences in the interviews between conditions. To this end we conducted two sets of analyses. First, we inspected audio-recordings of the interviews to see how often participants were shown the developing sketch. Faceto-face participants on average were shown the sketches more than twice as often as VMC participants $(M=16.55, S D=5.21$ vs. $M=8.05, S D=2.96$, respectively $), t(39)=$ $6.47, p<.001, d=2.00$.

Second, we looked to see whether the interviewer's questioning style differed between conditions, by transcribing the questions she had asked and then asking an independent rater - who was blind both to condition and to the experimental design and aims - to classify each question into one of seven categories. Questions about the face itself were judged as either open (e.g., "could you tell me more about the hair?"), closed (e.g., “is his nose about the right size?”), multiple-choice (e.g., "should I enlarge his top lip, his bottom lip, or both?"), leading (e.g., when the participant had previously described dark eyes, "I suppose his eyes need to be a bit darker, do they?"), or clarifications (“did you say he had small ears?”). Very few of the questions were evidently leading, but we adopted a liberal criterion by classifying as such even those that could be construed as minimally leading. In addition to these five categories, the rater also classified rapport questions (e.g., "is it warm enough in here for you?”) and technical questions (e.g., “can you see the picture clearly enough?”). The second author classified the questions from a subset of four interviews blind to 
condition, and the inter-rater agreement was $85 \%$ (Cohen's kappa $=.80)$. Our analysis is therefore based only on the first rater's classifications.

As the top part of Table 1 shows, we found no significant differences between conditions in terms of the total questions asked. However, we found some systematic differences in the types of questions asked. Predictably, technical questions were more frequent in VMC than in face-to-face interviews, $t(20.00)=7.06, p<.001, d=$ 2.17. In contrast, face-to-face interviews contained more questions about the face itself, $t(30.76)=2.47, p=.02, d=0.78$, in particular more closed questions, $t(28.44)=$ 3.04, $p<.01, d=0.96$, and more clarification questions, $t(26.46)=2.41, p=.02, d=$ 0.76. No other differences were significant.

[INSERT TABLE 1 ABOUT HERE]

\section{STUDY 1 - EVALUATION PHASE}

Next, we used two tasks to evaluate the quality of the composites produced, and to look for effects of interview format. Before doing so, 20 volunteers used 7point scales to rate the distinctiveness and memorability of all 42 target photos. There were no significant differences between the faces shown in the VMC versus face-toface conditions [Distinctiveness, $M=3.52$ vs. 3.55 respectively, $t(19)=0.47, p=.64$; Memorability, $M=3.72$ vs. 3.77 respectively, $t(19)=0.83, p=.42]$. These ratings confirm that we should not expect differences between conditions solely on the basis of the faces shown.

\section{Rating Task}

A new group of 39 students (32 females, 7 males; mean age $=20.00, S D=4.11$ ) participated for course credit. Each volunteer received a booklet; on each page was a target photo on the left, and the matching sketch on the right, both approximately $15 \mathrm{x}$ $12 \mathrm{~cm}$ in size. Using 7-point scales ( $1=$ Not a close match; 7= Very close match), 
volunteers rated each sketch on seven dimensions: [1] overall likeness; [2] age; [3] hair; [4] eyes and eyebrow region; [5] nose and mouth region; [6] face shape; and [7] distances between the facial features. Importantly, volunteers were not told that the sketches were based on verbal descriptions; this omission ensured their ratings were based on absolute match rather than any considerations about how good a likeness could be expected given the circumstances.

\section{Results}

First, we averaged ratings across all 42 composite sketches for each of the seven dimensions. The sketches were considered reasonable matches to the target photos: the overall likeness was rated 3.63 out of $7(S D=0.72)$. The sketches were considered quite good matches in terms of age $(M=4.43, S D=0.72)$, hair $(M=4.14, S D=0.77)$, eyes and eyebrow region $(M=4.05, S D=0.71)$, nose and mouth region $(M=4.09$, $S D=0.74)$, face shape $(M=3.82, S D=0.82)$, and distances between facial features $(M=4.34, S D=0.78)$. Although these means are far from the positive extreme of the scale, they are nevertheless promising when we consider that the volunteers did not know the sketches were based solely on descriptions. Indeed, they are comparable to those made in other composite studies involving similar rating tasks (e.g., Frowd, Bruce, Smith, \& Hancock, 2008).

Most importantly, Table 2 shows several differences in these ratings between conditions. Composites created face-to-face were considered significantly better overall than those created via VMC. Further paired $t$-tests revealed that the same pattern was significant for three of the six individual characteristics.

\section{[INSERT TABLE 2 ABOUT HERE]}

Three final analyses based upon the volunteers' ratings are interesting to add. First, it is noteworthy that the $18 \mathrm{VMC}$ sketches produced with participants who had 
used VMC before were judged rather better $(M=3.99, S D=0.74)$ than the three VMC sketches produced with novices $(M=3.39, S D=0.82)$. Second, across all 42 participants the mean overall likeness ratings attributed to sketches was not significantly correlated with any of the question frequency variables discussed above (see Table 1). Finally, the mean overall match ratings did not correlate with the number of times the participant viewed the sketch, $r(39)=.03, p=.84$.

\section{Sorting Task}

Twenty volunteers (10 females, 10 males; mean age $=24.50, S D=6.25)$ received a booklet featuring a target photo on each page alongside its matching sketch. Participants were asked to sort the 42 pages into their preferred order, from the best to the poorest match.

\section{Results}

For each participant, we calculated the mean rank allocated to composites created face-to-face, and those created via VMC. Results showed that face-to-face composites were on average ranked higher/better $(M=20.18 ; S D=1.02)$ than were VMC composites $(M=22.82 ; S D=1.02)$. Again, the difference was numerically small, but significant, $t(19)=5.85, p<.001, d_{z}=1.30$. Of the 10 sketches ranked highest, 4 were from the VMC condition; of the 10 sketches ranked lowest, 6 were from the VMC condition.

\section{STUDY 2 - INTERVIEW PHASE}

The results of Study 1 suggest that remote Cognitive Interviewing could be less effective than the traditional face-to-face format. However, we have argued that conducting interviews remotely might be useful when it is impracticable to conduct a face-to-face interview in a timely manner; it is therefore encouraging to observe that several of the sketches created via VMC were nonetheless among those rated most 
effective overall. Our results suggest that remote interviewing could still be a useful technique for eliciting quality facial composites when face-to-face interviews are not possible, and that looking to maximize the efficacy of remote interviews might be a productive avenue for exploration. In Study 1, VMC participants were shown the developing composite sketches via two methods_-via the webcam and via a digital photograph that was sent electronically to them. In Study 2 we examined whether one of these two presentation methods might facilitate better composite production than the other.

\section{Method}

\section{Participants and Design}

Twenty adults, either university students or staff $(n=7)$ or members of the university's local community $(n=13)$, responded to advertisements. The sample comprised 5 males and 15 females, with ages ranging from 29 to $65(M=44.40, S D=$ 11.16). Unlike in Study 1 where most VMC participants had used VMC before, here only six said they had done so.

As a means to explore the advantages and disadvantages of different techniques for conducting remote interviews, each participant was randomly allocated one of the two image-display methods used in Study 1: During the interviews in Session 2, participants were either shown the sketches via the webcam, or via digital photographs transferred electronically to their computer. The same interviewer as in Study 1 conducted all the interviews.

\section{Procedure}

Again participants attended two sessions individually on consecutive days. Session 1 was the same as in Study 1; this time target photos were taken from www.cityofsydney.nsw.gov.au. 
In Session 2, participants were shown into the interview room by the interviewer herself rather than the researcher from Session 1. However, interaction between the participant and interviewer at this stage was minimal; participants were simply shown into the room where Skype ${ }^{\complement}$ was running. The interviewer then left the room, and moved to another room where she began a video-call with the participant. During the interviews, participants were shown the developing sketch via only one of the two methods used in Study 1-either via webcam, or via a digital image transfer to their computer.

Interview sessions ranged in duration from 45-149 minutes $(M=85.60$ minutes, $S D=25.45)$, and examples of sketches are shown in Figure 1. All participants privately completed a short survey after their interview.

[INSERT FIGURE 1 ABOUT HERE]

\section{Results}

Participants in the webcam condition were shown the developing sketch considerably more often than were those in the digital image transfer condition $(M=$ $14.20, S D=3.26$ vs. $M=6.70, S D=1.89$, respectively), $t(18)=6.30, p<.001, d=2.81$. As in Study 1, an independent rater examined transcriptions of the questions asked in each interview, blind to condition, and classified each question. The second author also coded the data from four interviews blind to condition, and the inter-rater agreement was $90 \%($ Cohen's kappa $=.80)$. As the lower part of Table 1 shows, there were no systematic differences between conditions in terms of the total number of questions asked, or the total asked about the face in particular. However, in the digital image transfer condition, the interviewer asked significantly more multiple-choice questions, $t(18)=4.20, p<.01, d=1.88$, and technical questions, $t(9.80)=2.64, p=.03$, $d=1.18$. No other differences were significant. 


\section{STUDY 2 - EVALUATION PHASE}

\section{Rating task}

Twenty-five students (19 females, 6 males; mean age $=20.24, S D=2.74$ ) evaluated the composites. The procedure was identical to the rating task of Study 1, and participants gave seven match ratings for each of the 20 sketches. Volunteers were not told about the circumstances under which the sketches had been produced.

\section{Results}

Ratings were averaged across all 20 sketches for each of the seven facial dimensions. The results showed that the sketches were considered to be reasonable matches to the target photos: the overall likeness was rated 3.72 out of $7(S D=0.85)$. In terms of the apparent age of the targets, the sketches were again considered quite good matches $(M=4.44, S D=0.79)$. The hair was considered quite good $(M=4.09$, $S D=0.65)$, as were the eyes and eyebrow region $(M=3.92, S D=0.71)$, nose and mouth region $(M=3.86, S D=0.82)$, face shape $(M=3.79, S D=0.72)$, and distances between facial features $(M=4.21, S D=0.82)$.

The overall likeness of composites did not differ between those displayed to interviewees via webcam $(M=3.65, S D=0.94)$, and via digital image transfers $(M=$ 3.80, $S D=0.86), t(24)=1.26, p=.22, d_{z}=0.25$. Composites produced with the aid of a webcam were rated significantly better matches for the hair, $t(24)=5.28, p<.001, d_{z}=$ 1.06, and distances between facial features, $t(24)=2.06, p=.05, d_{z}=0.41$. However, composites produced with the aid of digital image transfers were rated significantly better matches for the eyes and eyebrow region, $t(24)=2.52, p=.02, d_{z}=0.50$, and face shape, $t(24)=2.42, p=.02, d_{z}=0.48$. Although these comparisons are based on a small number of composites and therefore must not be over-interpreted, the data suggest that both image-display methods had advantages and disadvantages, and so 
perhaps might be of most benefit when strategically used in conjunction. Indeed, this conclusion was supported by participants' comments: some in the webcam group commented that the image quality could have been clearer, whereas some in the image-transfer group felt that the transfer process made the interview slower and more difficult.

The 6 sketches produced with participants who had used VMC before were rated similarly to the 14 produced with novices $(M=3.78, S D=0.49$, and $M=3.70$, $S D=0.85$, respectively). Finally, Table 1 shows that the mean overall match ratings attributed to sketches did not significantly correlate with any of the question frequency variables reported above. These match ratings also had no significant correlation with the number of times the participant viewed the sketch, $r(18)=.11, p=$ 63 .

\section{SURVEY FINDINGS}

Recall that participants in the VMC condition of Study $1(n=21)$ and in Study 2 $(n=20)$ completed brief surveys regarding their experiences of the interviews. Most survey items were simple yes/no questions, used to ascertain whether basic interview requirements were met despite the lack of physical co-presence. This was the case: all participants agreed that the expectations of them had been clear, that the interviewer acknowledged them sufficiently, and that their motivation was maintained throughout. All but one agreed that they were made to feel relaxed and appreciated (the remaining participant did not answer these questions), and only one participant felt they received insufficient time to recall the face.

We were especially interested in the final survey item, which asked participants how they thought their remote interview fared relative to face-to-face communication. Participants provided a range of viewpoints; in particular using a simplistic content 
analysis we identified four key themes raised by multiple respondents.

\section{Challenging initial expectations}

Five participants indicated that they expected their remote interviews to be uncomfortable and difficult, but that they quickly adjusted to the interaction:

"I was pleasantly surprised how quickly you forgot how you were communicating."

"At first it's much more strange than face-to-face, especially as there was a bit of a delay in sound and picture, but after a while and once I'd got used to it, it seemed fine."

These comments support the notion that many witnesses might be reluctant to be interviewed remotely, but that this uncertainty would be quite easily overcome once an interview was underway.

\section{Pressure and focus}

Eight participants commented that they thought video-mediation made them feel less pressured and/or more relaxed, and a further four also thought it made them better able to focus on the task:

"It makes me feel more relaxed and give me enough time to think about the mental image."

"Made the interview easier. I found it easier to concentrate because I was alone in the room." 
“Actually it might even be that describing person's face during the sketch composite was less stressful thanks to the computer barrier than it would have been face-to-face."

"[p]erhaps less intimidating due to being able to look away without worrying about being rude."

The last of the above quotes is especially interesting because disengaging eyecontact can facilitate recall (e.g., Glenberg, Schroeder, \& Robertson, 1998; Perfect et al., 2008); therefore the possibility that video-mediation might encourage such disengagement warrants further investigation.

Nonetheless, it is worth noting that two participants made comments to the opposite effect, that they thought VMC felt more pressured than face-to-face communication would have done:

"It was a little more pressure feeling I had to think harder and try more than if I were face to face."

"It's not really too different, but face-to-face is more relaxed."

Developing a clearer appreciation of the individual differences that might determine whether video-mediation increases or decreases pressure and anxiety would help to understand the circumstances in which remote interviewing would be less or more appropriate. 


\section{Nonverbal communication}

Among the most common criticisms of the remote interviews was the difficulty some participants experienced with using nonverbal communication to facilitate their descriptions. Six participants suggested that they might have achieved better results had the interviewer been more able to see their gestures:

"Skype only allows you to see the other person's face. I think a faceto-face interview may have been better, because hand gestures / body gestures can be seen and may aid the artist's drawing."

"Relied more on verbal communication. Gestures were harder to use."

Again, though, this viewpoint was not universally shared:

"It is very similar because you have the opportunity to see gestures and nonverbal feedback in real-time"

\section{Technical issues}

Finally, comments about technical issues were mentioned by seven participants, although not all found these issues disruptive:

"Same, maybe Skype had occasional sound problem (stuttery) but not that bad." 
"A bit harder than FTF due to the odd technical difficulty and not being able to see the picture $1^{\text {st }}$ hand and point to it."

Three participants suggested that these issues seemed to slow the interviews down:

"Face-to-face communication would have been faster because of the video quality making it harder for me to see the sketches."

In fact, we know that $\mathrm{VMC}$ interviews were not significantly longer than faceto-face interviews in Study 1; nonetheless, the perception of slowness in the remote interviews - particularly when file transfers were used - might have contributed to the slightly poorer accuracy of the composites produced.

Overall, one of the most commonly expressed perceptions was that participants perceived no substantive difference from face-to-face communication - comments to this effect were made by eight people. This is an especially promising finding when we consider that most participants in Study 2 - and some in Study 1- had never used VMC technology before.

\section{DISCUSSION}

Ours appears to be the first research to examine the importance and necessity of interviewer presence when preparing facial composites. We argued that remote interviewing, if effective, could be an invaluable tool for investigative interviewers and sketch artists; however, this concept might in fact be less revolutionary than we presumed. Whilst conducting these studies we learned of an organization that is already providing this exact service: preparing composite sketches via a video- 
mediated interface. This discovery confirms the timeliness and importance of our preliminary findings, given the imperativeness of validating novel interview techniques with empirical data.

These data offer considerable promise for remote interviewing. In both studies, composites created via VMC were considered reasonably good matches to the targets. Moreover, most participants who were interviewed remotely gave positive feedback about their experiences: whereas some said that they would prefer a face-toface interview, many others said they perceived distinct benefits to remoteness in terms of their concentration, comfort, and perceptions of pressure and stress. These latter observations mirror those of previous research in which participants appeared to benefit from the social 'distancing' created by video-mediation (Doherty-Sneddon \& McAuley, 2000; Nash et al., 2013).

Nevertheless, the data from Study 1 suggest that remote interviews did not produce composites that were as effective as those produced face-to-face. These differences were small, but consistent. This finding could be seen as conflicting with those of Nash et al. (2013), who found no differences between the two formats in terms of participants' episodic recall in Cognitive Interviews. At least three possible explanations could account for this difference. First, the difference could be attributable to the fact that face-to-face participants were shown the developing sketches more often and were asked more questions about the face. There is little evidence for this explanation because none of these variables were significantly associated with the judged quality of the final sketches. A second possible explanation is that, as described above, the difficulty of verbalizing faces might mean that composite interviews rely more heavily on nonverbal communication, which many participants felt was attenuated in remote interaction. Finally, unlike Nash et al. we 
did not use a professional videoconferencing setup: our participants simply communicated via a regular Internet connection. Undoubtedly, the visual and auditory quality of some remote interviews in our studies was suboptimal, and so this might account for their somewhat poorer outcomes.

Irrespective of the exact mechanism, the superiority of composites created face-to-face has important implications, especially given that remote composite interviewing already appears to be an available service. Our data indicate that face-toface Cognitive Interviewing should currently be preferred over remote Cognitive Interviewing wherever possible; nevertheless, we must not forget the practical motivations for conducting interviews remotely. If an interview were conducted this way as a means to avoid lengthy delays, then the cost to composite quality caused by the lack of physical co-presence might sometimes be smaller than the cost incurred by allowing witnesses longer to forget the culprits' appearance. Unfortunately, unlike Nash et al. (2013) we did not include an experimental condition here in which participants undertook face-to-face interviews after a longer delay. A condition of this sort would have shown us which solution to the delay problem is likely to be better: taking part in a remote interview sooner, or waiting to have a face-to-face interview later. Given that delays of even a few days are often sufficient to severely undermine the quality of face composites (Frowd, Bruce, \& Hancock, 2008), we speculate that the former option might be preferable in at least some cases.

Of course, remote interviewing would not necessarily be appropriate for all witnesses or for all crimes. Indeed, our survey data suggested that some participants felt they were less anxious because of the video-mediation, whereas others felt they were more anxious. Without more objective measures of anxiety and other emotions, we are unable to examine whether there really were differences in anxiety and what 
effects these might have had; nonetheless these subjective impressions do at least suggest that there were large individual differences in how positively the videomediation was experienced by different participants. Future research should explore the advantages and disadvantages of video-mediated interviewing with different witness groups, especially vulnerable groups such as older adults who might be less comfortable and familiar with the technology (Czaja et al., 2006). Moreover, it would be useful to consider circumstances in which witnesses and victims might feel less or more prepared to give evidence remotely: for instance, a victim of a serious assault might feel more comfortable giving evidence to an interviewer who is not physically co-present, yet alternatively might feel more anxious and perhaps poorly treated to be interviewed in absentia. Understanding individual circumstances such as these should permit the most effective and appropriate application of novel interview techniques. To achieve these goals, it would be important for future research to improve on our methods in several ways. One way would be to compare the results obtained by multiple interviewers, who may elicit different patterns of results depending on their own familiarity and comfort with remote communication. A second way would be to use more ecologically-valid paradigms than ours — such as by viewing target faces in motion and situated within a broader event context, rather than static photographs (e.g., Frowd, Bruce, Smith, et al., 2008). Indeed, using dynamic event stimuli would be especially important given that static photographs offer only limited opportunity for interviewees to benefit from certain Cognitive Interview components, such as context reinstatement and 'report everything'. A third improvement would be to use a study paradigm that lends itself to quantifying the effectiveness of the composites with actual identification data; that is, by assessing whether people who are actually familiar with the target would be able to recognize him or her from the sketch (as per 
e.g., Frowd, Bruce, \& Hancock, 2008). Such extensions of the present investigation would improve our ability to generalize the findings and to make confident policy recommendations.

Finally, it would be interesting to test the effectiveness of remote interviews when using modern composite systems such as E-FIT and EvoFit, instead of sketch artists. Given that trained sketch artists often still outperform other systems, though (Davies \& Valentine, 2007; Frowd et al., 2005), it is worth noting that remote interviewing could permit police to draw upon the skills of artists more regularly than has heretofore been feasible. As forensic artistry itself moves into the digital age, perhaps a revival of the sketch artist could be a possible future for the science and practice of creating facial composites. 


\section{References}

Association of Chief Police Officers (2009). Facial identification guidance 2009. Retrieved from www.acpo.police.uk/documents/crime/2009/200911CRIFIG01.pdf.

Brace, N. A., Pike, G. E., Allen, P., \& Kemp, R. I. (2006). Identifying composites of famous faces: Investigating memory, language and system issues. Psychology, Crime \& Law, 12, 351-366.

Braun S. (2011). Recommendations for the use of video-mediated interpreting in criminal proceedings. In S. Braun \& J. L. Taylor (Eds.), Videoconference and remote interpreting in criminal proceedings (pp.265-287). Guildford:

University of Surrey.

Collins, R., Lincoln, R., \& Frank, M. G. (2002). The effect of rapport in forensic interviewing. Psychiatry, Psychology, \& Law, 9, 69-78.

Council of the European Union (2009). Videoconferencing as a part of European ejustice: The essentials of videoconferencing in cross-border court proceedings. Retrieved from http://dx.doi.org/10.2860/3549.

Czaja, S. J., Charness, N., Fisk, A. D., Hertzog, C., Nair, S. N., Rogers, W. A., et al., (2006). Factors predicting the use of technology: Findings from the Center for Research and Education on Aging and Technology Enhancement (CREATE). Psychology \& Aging, 21, 333-352.

Davies, G., \& Valentine, T. (2007). Facial composites: Forensic utility and psychological research. In R. C. L. Lindsay, D. F. Ross, J. D. Read, \& M. P. Toglia (Eds.), Handbook of eyewitness psychology. Volume II: Memory for people. (pp. 59-83). Mahwah NJ: Erlbaum. 
Deffenbacher, K. A., Bornstein, B. H., McGorty, K. E., \& Penrod, S. D. (2008).

Forgetting the once-seen face: Estimating the strength of an eyewitness's memory representation. Journal of Experimental Psychology: Applied, 14, 139150.

Doherty-Sneddon, G., \& McAuley, S. (2000). Influence of video-mediation on adultchild interviews: Implications for the use of the live link with child witnesses. Applied Cognitive Psychology, 14, 379-392.

Ebbinghaus, H. (1885). Memory: A contribution to experimental psychology. Leipzig: Duncker \& Humblot.

Ellis, H. D., Shepherd, J. W., \& Davies, G. M. (1980). Deterioration of verbal descriptions of faces over different delay intervals. Journal of Police Science \& Administration, 8, 101-106.

Fisher, R., \& Geiselman, E. (1992). Memory-enhancing techniques for investigative interviewing: The cognitive interview. Springfield: Charles Thomas.

Frowd, C., Bruce, V., \& Hancock, P. J. B. (2008). Changing the face of criminal identification. Psychologist, 21, 668-672.

Frowd, C. D., Bruce, V., Smith, A. J., \& Hancock, P. J. B. (2008). Improving the quality of facial composites using a holistic cognitive interview. Journal of Experimental Psychology: Applied, 14, 276-287.

Frowd, C. D., Carson, D., Ness, H., McQuiston-Surrett, D., Richardson, J., Baldwin, H., et al. (2005). Contemporary composite techniques: The impact of a forensically-relevant target delay. Legal \& Criminological Psychology, 10, 6381.

Fullwood, C. (2007). The effect of mediation on impression formation: A comparison of face-to-face and video-mediated conditions. Applied Ergonomics, 38, 267- 
273.

Fullwood, C., \& Finn, M. (2010). Video-mediated communication and impression formation: An integrative review. In A. C. Rayler (Ed.), Videoconferencing: Technology, impact, and applications (pp. 35-55). Hauppauge, NY: Nova Science Publishers.

Gabbert, F., Hope, L., \& Fisher, R. P. (2009). Protecting eyewitness evidence: Examining the efficacy of a self-administered interview tool. Law \& Human Behavior, 33, 298-307.

Glenberg, A. M., Schroeder, J. L., \& Robertson, D. A. (1998). Averting the gaze disengages the environment and facilitates remembering. Memory \& Cognition, 26, 651-658.

Hope, L., Gabbert, F., \& Fisher, R. P. (2011). From laboratory to the street: Capturing witness memory using the Self-Administered Interview. Legal \& Criminological Psychology, 16, 211-226.

Johnson, M. T., \& Wiggins, E. C. (2006). Videoconferencing in criminal proceedings: Legal and empirical issues and directions for research. Law \& Policy, 28, $211-$ 227.

Köhnken, G., Milne, R., Memon, A., \& Bull, R. (1999). The Cognitive Interview: a meta-analysis. Psychology, Crime \& Law, 5, 3-27.

Memon, A., Meissner, C. A., \& Fraser, J. (2010). The Cognitive Interview: A metaanalytic review and study space analysis of the past 25 years. Psychology, Public Policy, \& Law, 16, 340-372.

McQuiston-Surrett, D., Topp, L. D., \& Malpass, R. S. (2006). Use of facial composite systems in US law enforcement agencies. Psychology, Crime \& Law, 12, 505517. 
Minear, M., \& Park, D. C. (2004). A lifespan database of adult facial stimuli. Behavior Research Methods, Instruments, \& Computers, 36, 630-633.

Mitchell, J. E., Crosby, R. D., Wonderlich, S. A., Crow, S., Lancaster, K., Simonich, H., et al. (2008). A randomized trial comparing the efficacy of cognitivebehavioral therapy for bulimia nervosa delivered via telemedicine versus faceto-face. Behaviour Research and Therapy, 46, 581-592.

Morsella, E., \& Krauss, R. M. (2004). The role of gestures in spatial working memory and speech. American Journal of Psychology, 117, 411-424.

Nash, R. A., Houston, K. A., Ryan, K., \& Woodger, N. (2013). Remembering remotely: Would video-mediation impair witnesses' memory reports? Manuscript submitted for publication.

O'Conaill, B. Whittaker, S. Wilbur, S. (1993). Conversations over video conferences: An evaluation of the spoken aspects of video-mediated communication. HumanComputer Interaction, 8, 389-428.

O’Malley, C., Langton. S., Anderson, A., Doherty-Sneddon, G., \& Bruce, V. (1996). Comparison of face-to-face and video-mediated interaction. Interacting with Computers, 8, 177-192.

Perfect, T. J., Wagstaff, G. F., Moore, D., Andrews, B., Cleveland, V., Newcombe, S., et al. (2008). How can we help witnesses to remember more? It's an (eyes) open and shut case. Law \& Human Behavior, 32, 314-324.

Poulin, A. B. (2004). Criminal justice and videoconferencing technology: The remote defendant. Tulane Law Review, 78, 1089-1167.

Richardson, J., Stahl, D., Deal, M., \& Lowe, S. (2010). Standards and guidelines for forensic art and facial identification. Retrieved from https://www.theiai.org/disciplines/art/ForensicArtGuidelinesSGFAFI1stEd.pdf. 
Schooler, J. W., \& Engstler-Schooler, T. Y. (1990). Verbal overshadowing of visual memories: Some things are better left unsaid. Cognitive Psychology, 22, 36-71.

Shapiro, P. N., \& Penrod, S. (1986). Meta-analysis of facial identification studies. Psychological Bulletin, 100, 139-156.

Shepherd, J. W., Gibling, F., \& Ellis, H. D. (1991). The effects of distinctiveness, presentation time and delay on face recognition. European Journal of Cognitive Psychology, 3, 137-145.

Storck, J., \& Sproull, L. (2006). Through a glass darkly: What do people learn in videoconferences? Human Communication Research, 22, 197-219.

Straus, S. G., Miles, J. A., \& Levesque, L. L. (2001). The effects of videoconference, telephone, and face-to-face media on interviewer and applicant judgments in employment interviews. Journal of Management, 27, 363-381.

Vallano, J. P., \& Schreiber Compo, N. (2011). A comfortable witness is a good witness: Rapport-building and susceptibility to misinformation in an investigative mock-crime interview. Applied Cognitive Psychology, 25, 960970.

Zajac, R., \& Henderson, N. (2009). Don't it make my brown eyes blue: Co-witness misinformation about a target's appearance can impair target-absent line-up performance. Memory, 17, 266-278. 
Table 1. Frequencies of question types in Study 1 and Study 2, and correlations of these frequencies with overall likeness ratings ascribed by independent judges. Standard deviations are in parentheses.

\begin{tabular}{|c|c|c|c|c|c|c|c|c|c|}
\hline \multirow[t]{2}{*}{ Condition } & \multicolumn{6}{|c|}{ Questions about the face } & \multirow[t]{2}{*}{ Rapport } & \multirow[t]{2}{*}{ Technical } & \multirow[t]{2}{*}{ Total } \\
\hline & Open & Closed & $\begin{array}{l}\text { Multiple- } \\
\text { choice }\end{array}$ & Leading & $\begin{array}{c}\text { Clarificatio } \\
n\end{array}$ & Total & & & \\
\hline \multicolumn{10}{|l|}{ Study 1} \\
\hline \multirow[t]{2}{*}{ Face-to-face } & 26.55 & 11.60 & $1.80(1.61)$ & $0.70(1.03)$ & 15.95 & 56.60 & $2.70(2.43)$ & $0.00(0.00)$ & 59.30 \\
\hline & $(6.79)$ & $(5.27)$ & & & $(8.14)$ & $(16.50)$ & & & $(16.53)$ \\
\hline \multirow[t]{2}{*}{ VMC } & 24.95 & $7.57(2.77)$ & $2.05(1.63)$ & $0.33(0.58)$ & 11.14 & 46.05 & $3.05(2.31)$ & $4.95(3.22)$ & 54.04 \\
\hline & $(6.67)$ & & & & $(3.76)$ & $(9.87)$ & & & $(12.07)$ \\
\hline Correlation with overall & -.09 & .12 & -.07 & .22 & -.03 & .01 & .01 & .02 & .01 \\
\hline likeness & $p=.48$ & $p=.38$ & $p=.58$ & $p=.09$ & $p=.85$ & $p=.97$ & $p=.93$ & $p=.87$ & $p=.93$ \\
\hline \multicolumn{10}{|l|}{ Study 2} \\
\hline \multirow[t]{2}{*}{ Webcam } & 18.70 & 15.40 & $0.40(0.70)$ & $1.10(1.37)$ & 11.50 & 47.10 & $4.60(2.32)$ & $1.00(0.67)$ & 52.70 \\
\hline & $(4.06)$ & $(5.93)$ & & & $(5.38)$ & $(9.41)$ & & & $(8.30)$ \\
\hline \multirow[t]{2}{*}{ Digital image transfer } & 21.20 & 14.10 & $1.80(0.79)$ & $2.60(2.01)$ & 12.50 & 52.20 & $4.60(1.84)$ & $3.70(3.16)$ & 60.50 \\
\hline & $(3.91)$ & $(4.43)$ & & & $(5.50)$ & $(10.14)$ & & & (11.90) \\
\hline Correlation with overall & .24 & .18 & .30 & .32 & .00 & .28 & .01 & .27 & .33 \\
\hline likeness & $p=.31$ & $p=.45$ & $p=.21$ & $p=.17$ & $p=1.00$ & $p=.23$ & $p=.95$ & $p=.26$ & $p=.16$ \\
\hline
\end{tabular}

Note: One interview in Study 1 was not fully recorded, therefore these data are based on $N=41$. In Study $2, N=20$. 
Table 2. Judges' ratings of the likeness to the target photos of composites created face-to-face and via VMC in Study 1. Ratings were on a 7-point scale; standard deviations are in parentheses.

\begin{tabular}{|c|c|c|c|c|c|}
\hline \multicolumn{6}{|c|}{ Interview method } \\
\hline \multirow[t]{2}{*}{ Rating } & Face-to- & VMC & $t$ & Significance & Effect size \\
\hline & face & & & $(p)$ & $\left(d_{z}\right)$ \\
\hline \multirow[t]{2}{*}{ Overall } & 3.77 & 3.49 & 5.14 & $<.001$ & 0.83 \\
\hline & $(0.71)$ & $(0.77)$ & & & \\
\hline \multirow[t]{2}{*}{ Age } & 4.47 & 4.39 & 1.34 & .19 & 0.22 \\
\hline & $(0.74)$ & $(0.74)$ & & & \\
\hline \multirow[t]{2}{*}{ Hair } & 4.32 & 3.96 & 6.00 & $<.001$ & 0.97 \\
\hline & $(0.81)$ & $(0.77)$ & & & \\
\hline \multirow[t]{2}{*}{ Eyes and eyebrows } & 4.11 & 3.99 & 1.94 & .06 & 0.31 \\
\hline & $(0.72)$ & $(0.76)$ & & & \\
\hline \multirow[t]{2}{*}{ Nose and mouth } & 4.33 & 3.85 & 9.91 & $<.001$ & 1.61 \\
\hline & $(0.77)$ & $(0.75)$ & & & \\
\hline \multirow[t]{2}{*}{ Face shape } & 3.81 & 3.82 & -0.07 & .95 & 0.01 \\
\hline & $(0.84)$ & $(0.83)$ & & & \\
\hline Distances between & 4.38 & 4.29 & 1.64 & .11 & 0.27 \\
\hline facial features & $(0.83)$ & $(0.77)$ & & & \\
\hline
\end{tabular}


Figure 1. Examples of target faces and composite sketches created during remote interviews in Study 2. Photos courtesy of the City of Sydney.
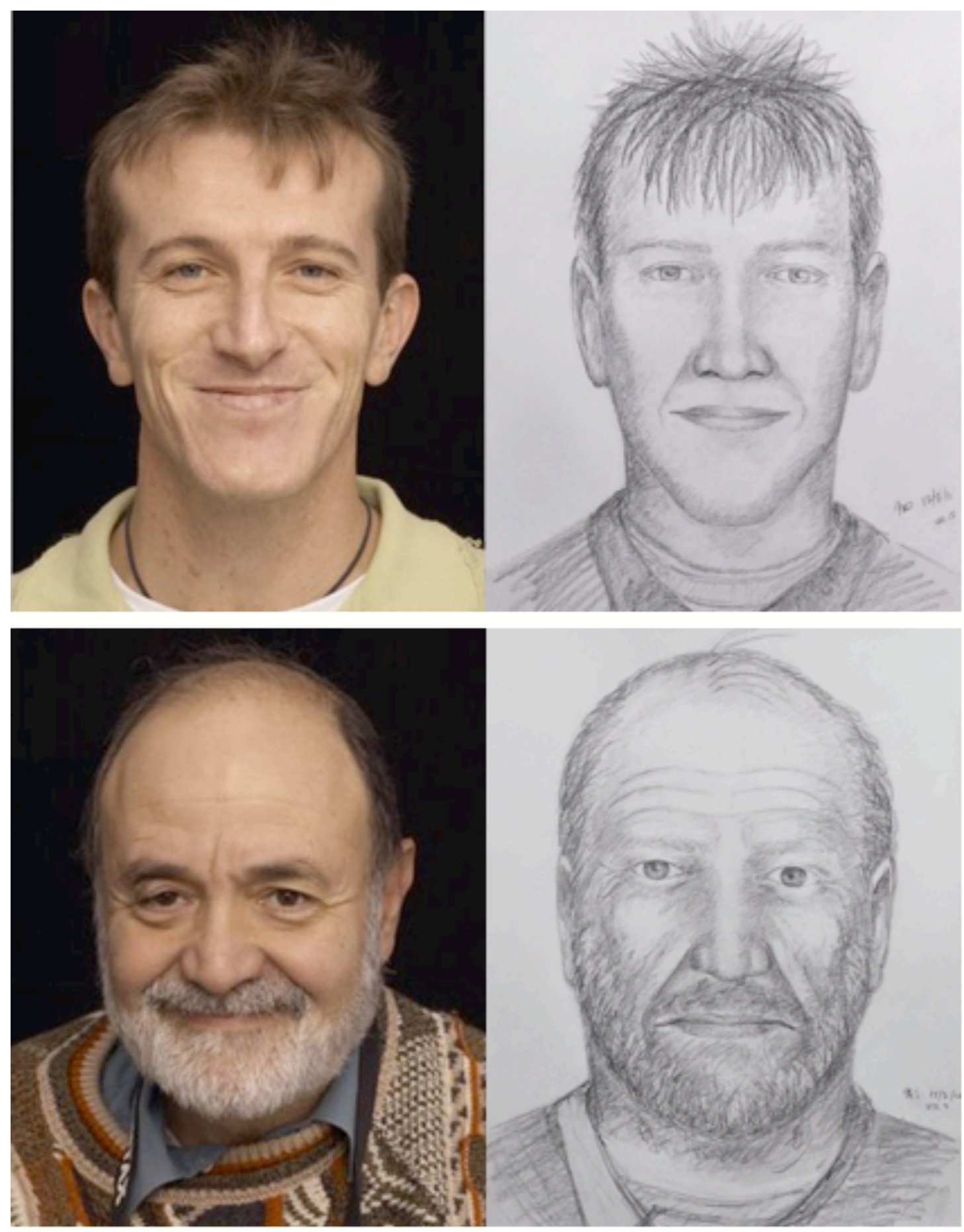